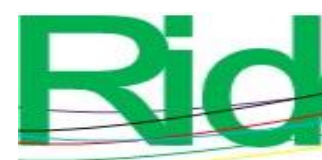

Revista Iberoamericana para la Investigación y el Desarrollo Educativo

\title{
Complejidad y método científico
}

\section{Complexity and Scientific Method}

\section{Complexidade e método científico}

\author{
Soid Ubaldo Alcalá Manuel \\ Multiversidad Edgar Morin, México \\ soidkalel@gmail.com \\ https://orcid.org/0000-0001-8699-3047
}

La enorme masa de saber cuantificable y utilizable no es más que veneno si se le priva de la fuerza liberadora de la reflexión.

JÜRGEN HABERMAS Y THEODOR ADORNO

\section{Resumen}

A menudo nos preguntamos, mientras observamos fenómenos naturales: ¿cómo funciona la ciencia? ¿puede explicarlo todo? La complejidad se presenta como un paradigma que puede ayudar a llenar los vacíos que ha dejado la ciencia positivista. Porque el sentido holístico de su carácter epistemológico podría ayudarnos a comprender mejor tanto el mundo natural como el social. Una comprensión que nos conduzca a la acción, pues los tiempos complejos actuales demandan la intervención oportuna del ser humano en los problemas que, en su mayoría, él mismo ha generado.

Palabras clave: ciencia, complejidad, método científico, racionalismo. 


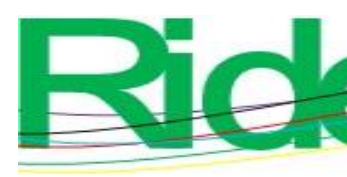

Revista Iberoamericana para la
Investigación y el Desarrollo Educativo
ISSN $2007-7467$

Bajo el esquema científico de la mecánica cuántica salieron a la luz —entre otraslas aportaciones de Ludwing Boltzmann (1899), Max Planck (1918), Niels Bohr (1922) y Werner Heinsenberg (1927), quienes, albergados en la noción de relatividad general, cambiaron el entramado conceptual del siglo determinista: se comenzaba a hablar de macrocosmos en vez de microcosmos, de incertidumbres en vez de certidumbres, de un universo dinámico y en expansión contrario a la idea newtoniana del universo finito y estático. Pero no solo eso, sino que además se integraban al lenguaje de la ciencia el concepto de azar como una necesidad de articular a la naturaleza con procesos complejos.

Aún más, siguiendo esta misma lógica, Tomas Kuhn (1922-1996) en 1962 trataba de desentrañar los postulados de la "ciencia madura" al publicar su libro La estructura de las revoluciones científicas, donde conceptualizó a la ciencia normal como una "investigación basada en una o más realizaciones científicas pasadas reconocidas por alguna comunidad científica durante cierto tiempo, como fundamento para su práctica posterior” (Kuhn, 1971, p. 33). De dicho concepto emerge también el de paradigma como un conjunto de reglas y normas comunes para llevar adelante la práctica científica (Kuhn, 1971). Es decir, un paradigma permite proporcionar modelos de prácticas de investigación científica y posee por sí mismo una visión del mundo, con los valores y la trama conceptual que aglutina; y son, según Tomas Kuhn, los grandes hallazgos los que originan las revoluciones científicas (el momento en que una teoría se impone a otra).

Pero lo que provoca que aparezcan los paradigmas y se produzcan este tipo de revoluciones del saber científico son las crisis de la ciencia, son esas etapas de profunda inseguridad profesional que requieren de una respuesta precisa desde la comunidad científica en turno, ya que el científico, como buen profesional de la ciencia, como un ente del saber, debe tener la competencia necesaria para reaccionar a las tensiones del mundo desordenado en el que vive. Las crisis permiten reconstruir profundamente los paradigmas establecidos o, en su caso, si así lo amerita la ocasión, darle la bienvenida a uno nuevo.

Así, al desentrañar la trama conceptual de la ciencia, el físico y filósofo estadounidense se enfocó en lo que debería ser la función del quehacer científico. En efecto, hizo hincapié en que la labor fundamental de la ciencia es desarrollar el uso de nuevos procedimientos para el estudio y la resolución de los “enigmas" científicos, enigmas solucionables y que pudieran poner a prueba la creatividad y el ingenio de quien hace la investigación, pues hacer ciencia invita a buscar diferentes formas de estudiar un mismo problema con el fin de obtener cada vez mejores resultados.

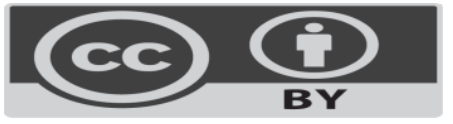




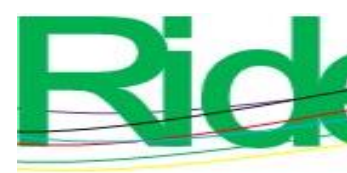

Revista Iberoamericana para la
Investigación y el Desarrollo Educativo
ISSN $2007-7467$

Con el paso del tiempo, las revoluciones científicas han transformado las visiones del mundo de las sociedades en turno. Por tal motivo, reconocerlas como elementos fundamentales para el desarrollo de la humanidad nos ayuda a vivir las incertidumbres con consciencia y, al mismo tiempo, favorece la evolución epistemológica de cada era planetaria. En ese sentido, las ideas y postulados de Edgar Morin (1984) encajan a la perfección para tratar de dar una explicación razonada acerca de la ciencia, el método científico y el surgimiento de los paradigmas.

Edgar Morin concuerda con Tomas Kuhn sobre la función elucidante de la ciencia. Para Morin, la razón principal de existencia de la ciencia es la resolución de enigmas y la disipación de misterios. Sin embargo, es cuidadoso al concebir a la ciencia como idea de progreso, ya que, a decir del propio pensador, una ciencia sin consciencia es ambivalente. Si bien el conocimiento nos otorga desarrollo, también puede convertirse en amenaza de autodestrucción (bomba atómica) si no se utiliza de manera adecuada.

Edgar Morin basa sus postulados en la idea pascaliana de una ciencia holística, en el sentido de tomar en cuenta las relaciones que guardan el todo y las partes de manera estrecha. Según este filósofo contemporáneo, hemos pasado mucho tiempo manejando un pensamiento disyuntivo que separa la naturaleza de la cultura y el objeto del sujeto; situación que no es nada sana, pues lo importante es respetar la autonomía de dichos agentes y establecer las relaciones necesarias para transformar nuestras estructuras cognitivas en pro de un conocimiento holístico y un desarrollo integral de la ciencia, donde nada esté de más y se abarquen cada una de las dimensiones existentes. Cabe señalar que esta concepción también fue influenciada por la teoría de sistemas de Bertalanffy.

En el mismo tenor, Edgar Morin redefine la idea del "progreso" acumulativo y lineal de la ciencia clásica para pensar en un progreso reflexivo, con autocrítica y en función de la incertidumbre, ya que consideraba que "demasiada información oscurece el conocimiento", lo que significa — extrapolando la idea al mundo real— que no por el hecho de tener avances científicos y tecnológicos la calidad de vida mejora en automático . Por tal razón, el progreso real reconoce la ignorancia, el azar, el orden y el desorden, es decir, la complejidad como elemento fundamental para el análisis, la reflexión y la transformación de la realidad.

La complejidad, según Edgar Morin, es una forma de "pensar desde el orden y el desorden a pesar de lo irracionalizable y lo inconcebible" (2008, p.15), es un mecanismo de procesos autogenerativos de conocimiento científico. Es lo embrollado, lo enmarañado, lo 


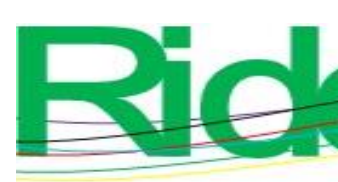

Revista Iberoamericana para la
Investigación y el Desarrollo Educativo
ISSN $2007-7467$

que no se puede simplificar dentro de la realidad, aquello que actúa bajo una lógica transdisciplinaria y totalizante. En términos concretos, lo complejo (Morin, 1988):

- $\quad$ Asocia al objeto y al entorno.

- Une el objeto a su observador.

- $\quad$ Reconoce al objeto como un sistema.

- Desintegra lo simple.

- $\quad$ Confronta la contradicción.

En ese sentido, la complejidad se erige como un método que toma en cuenta lo que la ciencia clásica había dejado de lado, ignorado o discriminado, pues concibe al progreso a través del reconocimiento y la denuncia del error, de lo falso y del engaño. ¿Podríamos decir entonces que lo planteado por Edgar Morin es un paradigma? Sí, el paradigma de la complejidad.

Más adelante, Edgar Morin describe los principios generativos y estratégicos de su método. Cabe señalar que, en palabras de Morin, el método es precisamente aquella "herramienta generativa de estrategias" (Morin, 2002) y una estrategia es el arte mismo, con su dosis múltiple de reflexividad. A continuación, se describen brevemente los siete principios:

Principio sistémico u organizacional: hace referencia a las ideas de Blaise Pascal (1623-1662) y Ludwig von Bertalanffy (1901-1972): estudiar el todo a partir de las partes y las partes a partir del todo, sin olvidar que están relacionados estrechamente.

- Principio hologramático: se refiere a entender al individuo como un holograma de la sociedad, como una pequeña muestra de la misma.

- $\quad$ Principio de retroactividad: alude a la idealización de un bucle que rompe con la causalidad lineal de la ciencia clásica y que se reconstruye a sí mismo de manera constante.

- $\quad$ Principio de recursividad: este es uno de los principios fundamentales y hace hincapié en una dinámica de autoproducción entre el sujeto y el objeto, en donde ambos son dependientes el uno del otro.

- Principio de autonomíaldependencia: es un principio que busca una autoorganización para desarrollar la autonomía a partir del entorno donde el sujeto se desarrolla.

- $\quad$ Principio dialógico: las diferentes lógicas o formas de pensar pueden complementarse y asociarse de forma compleja. 


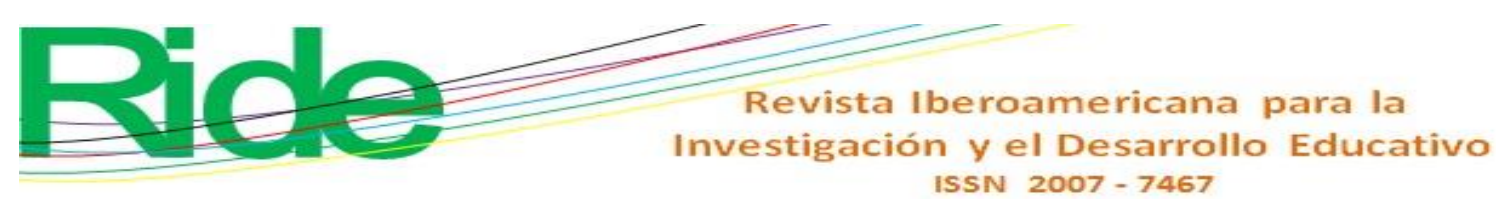

Mientras que el pensamiento complejo toma en cuenta las condiciones de cada contexto para la explicación de su realidad, sin interés alguno de estandarización.

Otro aspecto importante que diferencia estos tipos de pensamiento tiene que ver con la causalidad y temporalidad. El pensamiento complejo contempla la evolución histórica del pensamiento, su injerencia en el futuro y el eterno diálogo con el pasado, es decir, que si es necesario retomar alguna idea o técnica del pasado para solucionar un problema del presente, el pensamiento complejo lo acepta y lo respalda, he ahí la causalidad compleja. Sin embargo, en el pensamiento simple resulta inconcebible volver a las ideas del pasado, pues atentaría contra la causalidad lineal que defiende.

También provoca ruptura entre ambos pensamientos el tema del orden y el desorden, pues mientras el pensamiento simple siga padeciendo de cierto tipo de trastorno obsesivo compulsivo en referencia a los elementos del universo, seguirá desaprovechando la oportunidad de aprender de la riqueza epistemológica que existe dentro del desorden. Por el contrario, un pensamiento complejo contempla a la aleatoriedad como una oportunidad de encuentro entre el orden y el desorden, donde nada puede ser tan perfecto e impecable, ya que el universo mismo y el ser humano en su totalidad son nociones complejas que se reconstruyen entre sí día con día.

Por último, la disyunción entre el objeto y el sujeto también implica la distinción del pensamiento simple del complejo. La naturaleza positivista del primero se basa en un pensamiento objetivo, que indica que solo las acciones del sujeto pueden repercutir en el objeto, pues este último es un componente estático. Por su parte, el pensamiento complejo promueve tener en cuenta al objeto y al sujeto como elementos que se complementan en la interacción, es decir, tanto el sujeto puede transformar al objeto como el objeto al sujeto. Algo muy se suscita en la concepción de Freire (1965) de educador-educando y educandoeducador, lo cual para la ciencia tradicional resultaría por el momento inconcebible.

Por tal razón, se puede pensar que la complejidad ha sido el paradigma en respuesta a la crisis civilizatoria actual. Así pues, la revolución científica de la que ya formamos parte nos invita a tener la mente abierta y comprender que los nuevos tiempos requieren también de nuevos métodos, técnicas y estrategias para el estudio, análisis y reflexión sobre los problemas planetarios. La complejidad debería convertirse, entonces, en ese armazón teórico-práctico que nos permita navegar con equilibrio entre las aguas calmadas del método científico y los riesgosos vendavales de la ignorancia. La complejidad es azar, incertidumbre, 


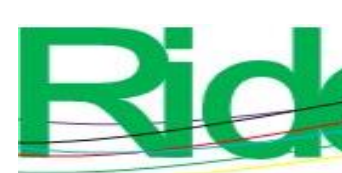

Revista Iberoamericana para la
Investigación y el Desarrollo Educativo

ISSN $2007-7467$

recursividad y retroactividad; es uno de los eslabones epistemológicos más fuertes dentro de la evolución del pensamiento contemporáneo.

Es decir, entendemos que los principios de incertidumbre y la influencia del azar en la configuración de las sociedades actuales demanda enfoques teóricos que las tomen en cuenta. Para tal caso, el paradigma de complejidad es una de las mejores opciones desde donde se puede intervenir.

Pensar y actuar desde la complejidad nos demandará, eso sí, una serie de tareas acordes a la naturaleza holística del enfoque. Sin embargo, en función del mejoramiento de las condiciones de vida de los agentes que se involucren dentro de las sociedades en las que actuemos, sin duda que valdrá la pena afrontar este reto complejo.

\section{Conclusiones}

A raíz de los temas revisados en el presente ensayo podemos concluir que existen otras formas de ver la realidad distintas a la que nuestra formación inicial nos ha mostrado. En efecto, tanto en la educación básica como en la media superior y superior la ciencia clásica ha sido el sustento teórico de los planes y programas de estudio. Aunque eso no significa que uno no pueda reflexionar sobre su propia formación, sobre todo tomando en cuenta que el conocimiento está en constante cambio y que como sujetos debemos adecuarnos a dichos cambios. Por tal motivo, en los tiempos de incertidumbre de este siglo XXI conviene replantearse las metodologías, técnicas y enfoques de investigación, debido a que la ciencia clásica no es la única forma posible para la explicación de los fenómenos naturales y sociales.

Aunado a lo anterior, es necesario aventurarse desde los enfoques transdisciplinares, donde se busca la reconciliación de la ciencia y la filosofía, donde se promueve la emancipación real y se contemplan procesos complejos de reflexión y acción. Es necesario, entonces, empezar a vivir en la complejidad, pues complejo es el mundo y complejos somos todos. 

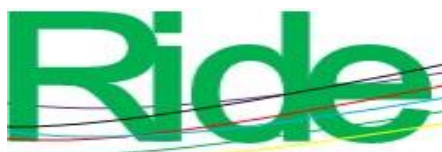

Revista Iberoamericana para la Investigación y el Desarrollo Educativo

ISSN 2007 - 7467

\section{Referencias}

Carvajal, L. E. (1993). Las revoluciones científicas del siglo XX. Cuadernos del Mundo Actual, (4), 1-31.

Freire, P. (1965). La educación como práctica de la libertad. México: Siglo XXI Editores.

Kuhn, T. (1971). La estructura de las revoluciones científicas. Ciudad de México, México: Fondo de Cultura Económica.

Morin, E. (1983). El método II. La vida de la vida. Madrid, España: Cátedra.

Morin , E. (1984a). La métamorphose de Plozévet: Commune de France. France, París: LGF.

Morin, E. (1984b). Ciencia con consciencia. Barcelona, España: Anthropos.

Morin, E. (1988). El paradigma de la complejidad. Camacol, (60)

Morin, E. (1992). El método IV. Las ideas. Madrid, España: Cátedra.

Morin, E. (2002). Educar en la era planetaria. Barcelona, España: Gedisa. 